\title{
Interhemispheric conjugate effect in longitude variations of mid-latitude ion density
}

\author{
Yiding Chen ${ }^{1,2,3,4, *}$, Libo Liu ${ }^{1,2,3,4}$, Huijun Le ${ }^{1,2,3,4}$, and Hui Zhang ${ }^{1,2,3,4}$ \\ ${ }^{1}$ Key Laboratory of Earth and Planetary Physics, Institute of Geology and Geophysics, Chinese Academy of Sciences, \\ Beijing 100029, PR China \\ 2 Innovation Academy for Earth Science, CAS, Beijing 100029, PR China \\ ${ }^{3}$ Beijing National Observatory of Space Environment, Institute of Geology and Geophysics, Chinese Academy of Sciences, \\ Beijing 100029, PR China \\ ${ }^{4}$ College of Earth and Planetary Sciences, University of Chinese Academy of Sciences, Beijing 100029, PR China
}

Received 18 January 2019 / Accepted 23 October 2019

\begin{abstract}
Earlier incoherent scatter radar measurements revealed upward topside ion fluxes in the summer and downward fluxes in the winter at mid-latitudes at night; a summer to winter interhemispheric coupling was accordingly inferred. However, this interhemispheric coupling through the plasmasphere is difficult to confirm directly from observations. A possible result induced by this coupling is interhemispheric conjugacy of the mid-latitude ionosphere. In this paper, interhemispheric conjugate effect in longitude variations of mid-latitude total ion density $\left(N_{i}\right)$ is presented, for the first time, using the Defense Meteorological Satellite Program (DMSP) measurements; northern and southern $N_{i}$ longitude variations at 21:30 LT are similar between magnetically conjugate mid-latitudes around solar minimum June Solstice of 1996. The conjugate effect after sunset also occurs around the June Solstice in other solar minimum years but disappears when solar activity increases. We suggested that mid-latitude interhemispheric coupling is responsible for the conjugate effect. Neutral wind induced ionospheric transport causes topside longitude variations via upward diffusion at summer mid-latitudes; this further induces similar longitude variations of topside $N_{i}$ at winter mid-latitudes via the summer to winter interhemispheric coupling. The conjugate effect occurs only inside the plasmapause where magnetic flux tubes are closed and the plasma in these tubes can stably corotate with the Earth. The conjugate effect not only proves mid-latitude interhemispheric coupling through the plasmasphere, but also implies that neutral wind induced transport can affect ionospheric coupling to the plasmasphere at mid-latitudes.
\end{abstract}

Keywords: mid-latitude ionosphere / topside ionosphere / ion density / longitude variation / interhemispheric conjugate effect

\section{Introduction}

Ionospheric longitude variations, which refer to ionospheric differences between longitudes at fixed local times, are important spatial structures of the ionosphere. Longitude variations of the low- and mid-latitude ionosphere should be related to the factors such as the longitude differences in ionospheric dynamic processes and in the thermosphere (e.g., Liu et al., 2009; England et al., 2010; Burrell et al., 2012), since solar irradiance conditions are equivalent at different longitudes for any given latitude and local time. Thus, they are usually good topics for investigating ionospheric dynamic effects and the coupling between the ionosphere and the thermosphere.

\footnotetext{
*Corresponding author: chenyd@mail.iggcas.ac.cn
}

An important longitude variation pattern of the low-latitude ionosphere is the wave number four structure (e.g., Immel et al., 2006; Wan et al., 2008), which is characterized by wave-like electron density variations (with four electron density peaks separated by four troughs) along longitudes in the dip equator region. This wave-like longitude variation was suggested to be closely related to the longitude differences in equatorial upward plasma drift (e.g., Fejer et al., 2008; Ren et al., 2009) that drives the fountain effect (Hanson \& Moffett, 1966) and in the thermosphere (e.g., Liu et al., 2009); these longitude differences are mainly caused by the non-migrating tides from the lower atmosphere (e.g., England et al., 2006; Immel et al., 2006; Wan et al., 2012). The longitude differences in the fountain effect play a crucial role in the longitude variations of the equatorial ionosphere; they tend to result in similar longitude 
variations at the north and south of the dip equator (e.g., Tulasi Ram et al., 2009), namely, conjugate longitude variations at low-latitudes.

This paper focuses on mid-latitude longitude variations, which are usually related to the geomagnetic field configuration. Geomagnetic declination and inclination are longitudinally dependent (Finlay et al., 2010); this can lead to longitude differences in the mid-latitude ionosphere by affecting neutral wind induced field-aligned transport (e.g., Horvath \& Lovell, 2009a; Zhang et al., 2012). For example, the geomagnetic field modulation on neutral-ion interactions causes a longitudinal two-peak structure of electron density at northern mid-latitudes and a one-peak structure at southern mid-latitudes (e.g., Jee et al., 2009; Lin et al., 2010; Chen et al., 2016). Namely, under the influences of geomagnetic configuration, neutral wind induced ionospheric transport plays a dominant role in midlatitude longitude variations. Longitude variations are usually not conjugate between northern and southern mid-latitudes, owing to the difference of geomagnetic configuration between the two hemispheres.

It should be pointed out that the mid-latitude ionosphere closely couples with the overlying plasmasphere in addition to being controlled by local ionospheric transport processes. The plasmasphere supplies charged particles to the underlying ionosphere at night owing to the decay of the $\mathrm{F}_{2}$ layer. Mid-latitude longitude variations are possibly affected by the plasmasphere under that condition. Moreover, it can be further speculated that the northern and southern mid-latitude ionospheres may interact if there is an interhemispheric coupling inside the plasmasphere, owing to that the plasmasphere couples with both the northern and southern ionospheres. Topside plasma flux at a fixed location was found to be upward in the summer and downward in the winter at night basing on mid-latitude Millstone Hill incoherent scatter radar measurements (Evans \& Holt, 1978), suggesting the presence of summer to winter interhemispheric coupling (the plasmasphere supplies charged particles to the winter nighttime ionosphere, meanwhile it is maintained from the summer hemisphere). The hypothesis of interhemispheric coupling was supported by the similarities of nighttime ionospheric behavior at nearly magnetically conjugate locations (e.g., Jakowski \& Förster, 1995). And the summer to winter interhemispheric coupling has been used to explain some ionospheric phenomena such as the formation of nighttime winter anomaly (e.g., Jakowski et al., 2015 and references therein) and the distribution of winter nighttime enhancement in ionospheric electron density (e.g., Chen et al., 2015).

Another possible result of the interaction between the northern and southern mid-latitude ionospheres is the conjugacy in the longitude variations of plasma density, especially in the topside where field-aligned diffusion plays a dominant role in the plasma density distribution. This conjugacy has not been investigated in previous studies. In this paper, longitude variations of topside total ion density $\left(N_{i}\right)$ were investigated using the in situ measurements of the Special Sensor for Ions, Electrons and Scintillation (SSIES) instrument on board the DMSP satellites. Plasma transport from lower to higher altitudes significantly controls the topside ionosphere in the daytime; while the plasmasphere can affect the mid-latitude topside ionosphere in the nighttime only if the plasma flux is downward (as is the case at night in solar minimum winter, Evans \& Holt, 1978; this makes interhemispheric coupling possible). This study selected DMSP measurements at night around the June Solstice, when ionospheric conditions are unbalanced along the magnetic flux tubes, to examine mid-latitude interhemispheric coupling. Interhemispheric conjugate effect $\left(N_{i}\right.$ distributions along geomagnetic longitudes are similar between equivalent northern and southern geomagnetic mid-latitudes) was observed in $N_{i}$ longitude variations at solar minimum. We propose that the mechanism for this conjugate effect is the interhemispheric coupling of the mid-latitude ionosphere through the plasmasphere, in which neutral wind induced field-aligned transport in the summer hemisphere plays an important role during the period under consideration. Basing on this mechanism, the results imply that the mid-latitude ionospheric dynamic process driven by neutral winds is important for the coupling between the ionosphere and the plasmasphere.

\section{Data analyses and results}

The DMSP satellites are in the Sun-synchronous polar orbits at about $840 \mathrm{~km}$, a height where dynamic processes dominate the ionosphere, with inclinations of about $99^{\circ}$ and periods of about 101 min. The DMSP satellites have carried the SSIES instrument package to measure in situ plasma environment since the DMSP F8. The SSIES instrument package consists of an ion drift meter, an ion retarding potential analyzer, an ion total density trap, and an electron Langmuir probe (Greenspan et al., 1994; Rich, 1994); it can measure several parameters of the space plasma environment, including $N_{i}$ and ion fractional composition. In this study, the $N_{i}$ data measured by SSIES ion total density traps and the ion fractional composition (percentages of $\mathrm{H}^{+}, \mathrm{He}^{+}$, and $\mathrm{O}^{+}$) measured by SSIES ion retarding potential analyzers of the DMSP satellites were used. We used the DMSP data production that were archived as 4-second averages and provided at the web site of the University of Texas, Dallas. This dataset can be used to investigate the climatology of topside $N_{i}$ longitude variations in specific local time sectors.

The DMSP F12 satellite was operated in 09:30/21:30 LT meridian from August 1994 to July 2002 (a time range covering solar minimum to maximum). DMSP F12 nightside measurements in solstice season at solar minimum were used, since the northern and southern ionospheres are so unbalanced along the magnetic flux tubes under this condition that mid-latitude topside ion flux becomes downward in the winter while maintains upward in the summer before solar minimum midnight (Evans \& Holt, 1978), implying that interhemispheric coupling possibly takes place. In order to investigate average longitude variations of $N_{i}$, the measurements within \pm 30 days centered on the June Solstice day (61 days in total) of the solar minimum year 1996 were combined to ensure good spatial coverage of the data. The data with geomagnetic disturbances (geomagnetic activity index Ap was larger than 20 on the day when $N_{i}$ was measured or on the previous day, given the delay of geomagnetic activity influence on the ionosphere) were removed to exclude the effects of stronger geomagnetic activities. However, all of the data of 61 days around the June Solstice of 1996 were used, owing to that the geomagnetic activity level was low $(\mathrm{Ap}<20)$ during that period. The selected $N_{i}$ data were averaged using a moving window of longitude 
$20^{\circ} \times$ latitude $5^{\circ}$ in geographic coordinates with a moving step length of longitude $10^{\circ} \times$ latitude $5^{\circ}$ to obtain $N_{i}$ average distribution with longitudes and latitudes. The number of the data points within each bin (longitude $20^{\circ} \times$ latitude $5^{\circ}$ ) is larger than 200 (average number is $\sim 1000$ ) when calculating $N_{i}$ averages.

Figure 1a shows the average longitude and latitude variations of DMSP F12 $N_{i}$ at 21:30 LT around the June Solstice of 1996. The thick black lines denote zero geomagnetic declination and the thin gray lines are geomagnetic inclination isolines; both were calculated from the eleventh generation of the International Geomagnetic Reference Field model (Finlay et al., 2010). $N_{i}$ shows evident longitude variations in the Northern (summer) Hemisphere; for example, northern mid-latitude $N_{i}$ is higher at about $15^{\circ}-60^{\circ} \mathrm{E}$ and $105^{\circ}-210^{\circ} \mathrm{E}$ while lower at about $240^{\circ}-330^{\circ} \mathrm{E}$. This longitude structure distributes along geomagnetic inclination isolines to some extent. There are also significant longitude variations at mid-latitudes in the Southern (winter) Hemisphere, such as between the inclination isolines of $-45^{\circ}$ and $-60^{\circ}$. It is interesting that the longitude fluctuations of mid-latitude $N_{i}$ seem to be symmetric with respect to the dip equator between the Northern and Southern Hemispheres, indicating that the longitude variations are possibly interhemispheric conjugate within the framework of the geomagnetic field. In view of this, Figure $1 \mathrm{~b}$ shows $N_{i}$ distribution in magnetic apex coordinates (e.g., VanZandt et al., 1972; Laundal \& Richmond, 2017) to further confirm the interhemispheric conjugate effect in mid-latitude $N_{i}$ longitude variations. $N_{i}$ is higher at geomagnetic mid-latitudes, where it shows significant variations with geomagnetic longitudes, in both hemispheres. It is evident that $N_{i}$ longitude variations are very similar $\left(N_{i}\right.$ peaks at $\sim 120^{\circ}$ and $\sim 240^{\circ}$ along longitudes) between equivalent northern and southern mid-latitudes when the $N_{i}$ distribution is presented in geomagnetic coordinates; namely, mid-latitude $N_{i}$ longitude variations are interhemispheric conjugate. With increasing latitude in the Southern Hemisphere, $N_{i}$ shows significant drop-off at higher latitudes, making it difficult to distinguish the longitude variation patterns. Thus, $\left(\delta N_{i}\right)_{\text {Mlon }}$ was calculated by removing $\left\langle N_{i}\right\rangle_{\text {Mlon }}$ (longitudinal average of $N_{i}$ at corresponding geomagnetic latitude) from Figure $1 \mathrm{~b}$ to highlight $N_{i}$ longitude fluctuations.

$$
\left(\delta N_{i}\right)_{\mathrm{Mlon}}=N_{i}-\left\langle N_{i}\right\rangle_{\mathrm{Mlon}}
$$

The latitudinal dependence of $N_{i}$ longitude variation patterns is clearly presented in terms of $\left(\delta N_{i}\right)_{\text {Mlon }}$, as shown in Figure 1c. $N_{i}$ longitude variations show significant interhemispheric conjugate effect at mid-latitudes. With increasing latitude, however, the longitude variation pattern changes so that the interhemispheric conjugate effect vanishes.

We further compared the northern and southern longitude variations of $N_{i}$ in more detail for different conjugate latitude bands. Figure 2 shows the northern (red) and southern (blue) longitude fluctuations of $\left(\delta N_{i}\right)_{\text {Mlon }}$ for six geomagnetic latitude band pairs to investigate the dependence of the conjugate effect on latitudes. The average longitude variation of $\left(\delta N_{i}\right)_{\text {Mlon }}$ in each latitude band was retrieved from the gridded average $N_{i}$ shown in Figure 1. $N_{i}$ longitude fluctuations are very similar between the Northern and Southern Hemispheres at geomagnetic lower- to mid-latitudes, especially for the latitude bands of $\pm 20^{\circ}- \pm 30^{\circ}$ and $\pm 30^{\circ}- \pm 40^{\circ}$. The similarity declines

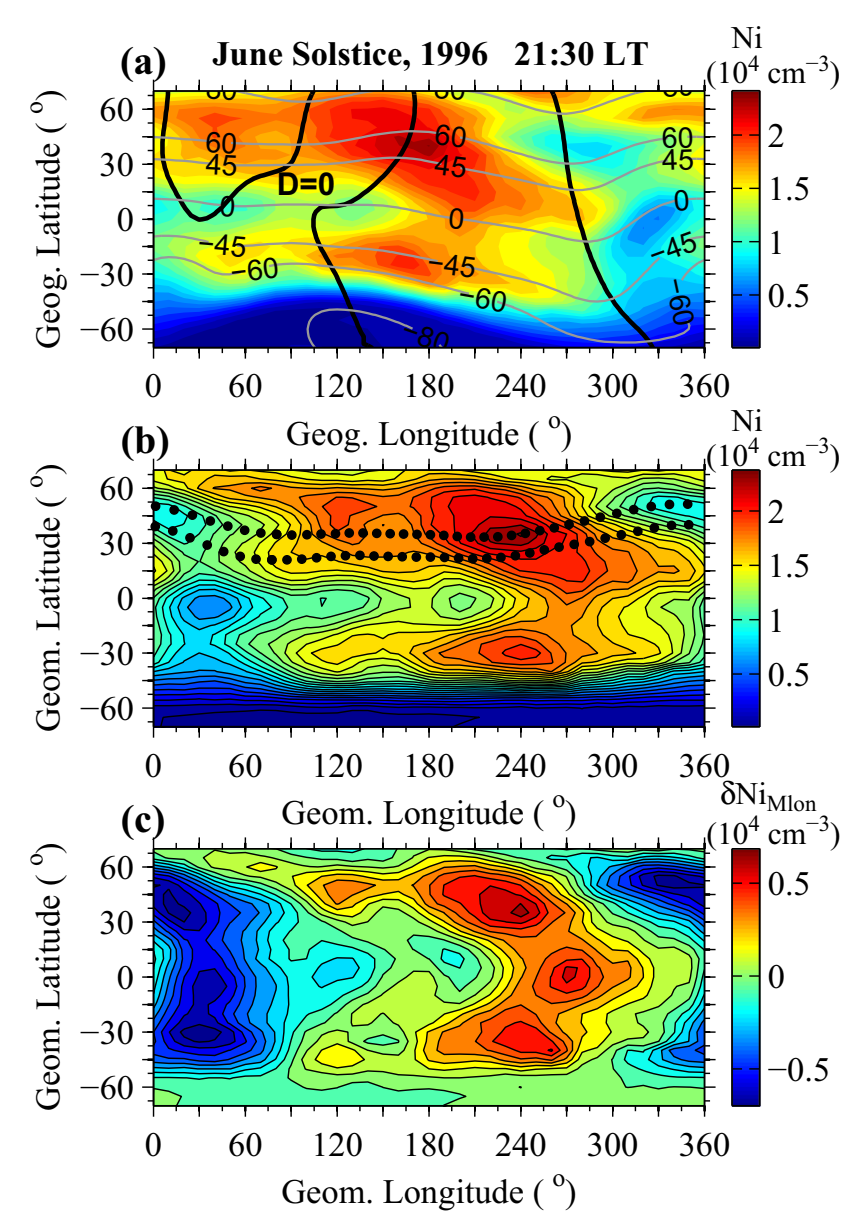

Fig. 1. (a) Longitude and latitude variations of DMSP F12 $N_{i}$ measured at nightside 21:30 LT around the June Solstice of 1996. The thick black lines denote that geomagnetic declination is zero and the thin gray lines are geomagnetic inclination isolines. (b) The distribution of $N_{i}$ in geomagnetic coordinates. Two black dotted lines denote the solar terminators at $300 \mathrm{~km}$ height at 21:30 LT (the upper line) and 20:30 LT, respectively. (c) $N_{i}$ longitude fluctuations with longitudinal averages removed for each geomagnetic latitude.

(see the correlation coefficient, cc) in the latitude bands of $\pm 50^{\circ}- \pm 60^{\circ}$; and the longitude variation patterns significantly change at southern higher latitudes so that the conjugate effect vanishes at the latitudes poleward of $\pm 60^{\circ}$. That means the interhemispheric conjugate effect occurs only within the geomagnetic latitude range from about $-60^{\circ}$ to about $60^{\circ}$; the boundaries of this latitude range are close to the plasmapause positions (e.g., Horvath \& Lovell, 2009b).

Seasonal dependence of the conjugate effect was investigated by comparing northern and southern $N_{i}$ longitude variations in different seasons. Figure 3 shows the average longitude and latitude variations of DMSP F12 $N_{i}$ at 21:30 LT around the March Equinox of 1996. Data of 46 days were used after removing the measurements under geomagnetic disturbance conditions (Ap $>20$ on the day when $N_{i}$ was measured or on the previous day, hereinafter the same). $N_{i}$ longitude variation is dominated by the wave number four structure (e.g., Immel et al., 2006; Wan et al., 2008) in the equatorial region. With increasing latitudes, mid-latitude longitude 

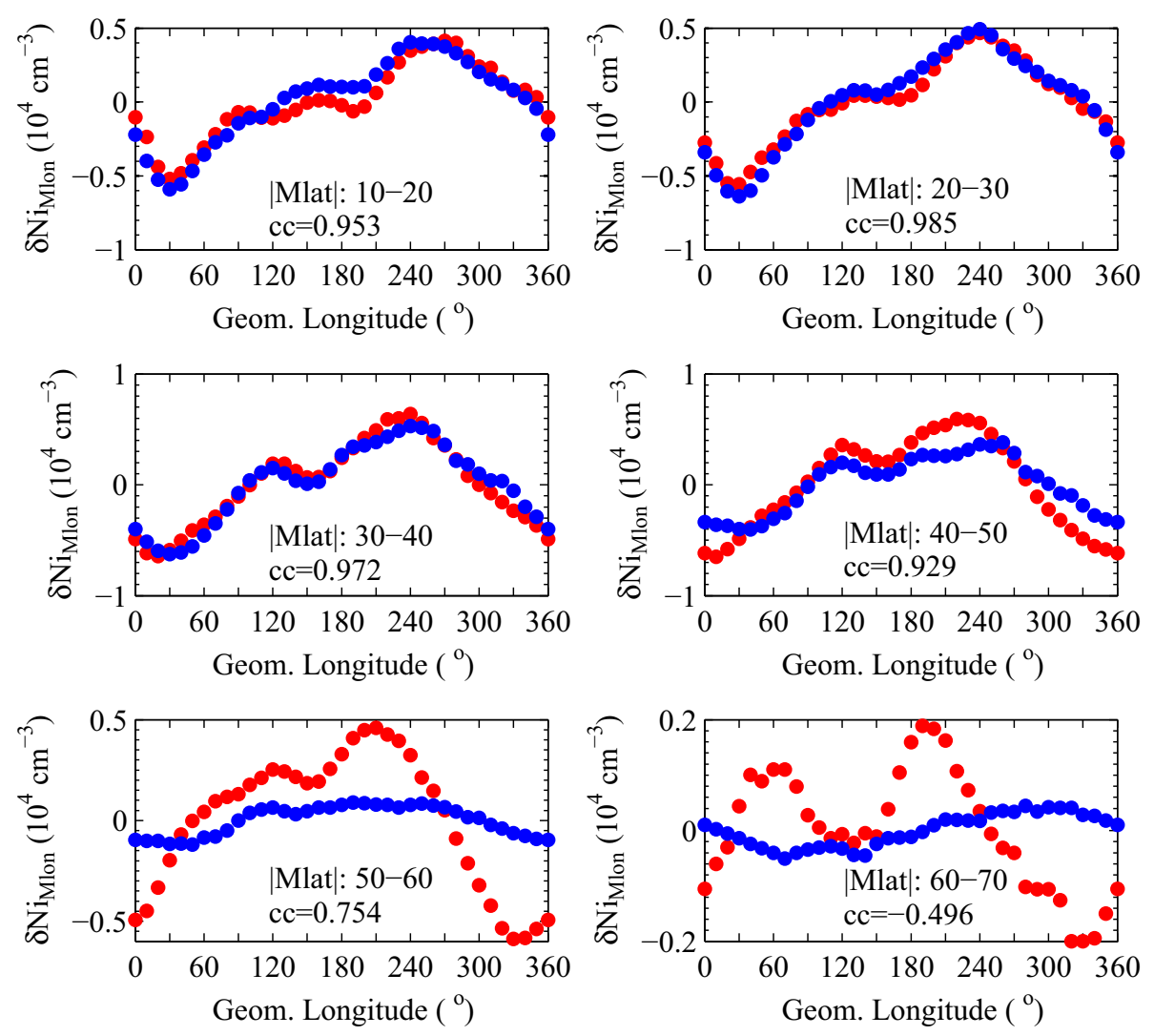

Fig. 2. Longitude fluctuations of $\left(\delta N_{i}\right)_{\text {Mlon }}$ calculated from DMSP F12 $N_{i}$ at 21:30 LT around the June Solstice of 1996 for six conjugate geomagnetic latitude bands. The red dots for northern latitude bands and the blue dots for southern latitude bands; cc is the correlation coefficient between the red and blue dots.

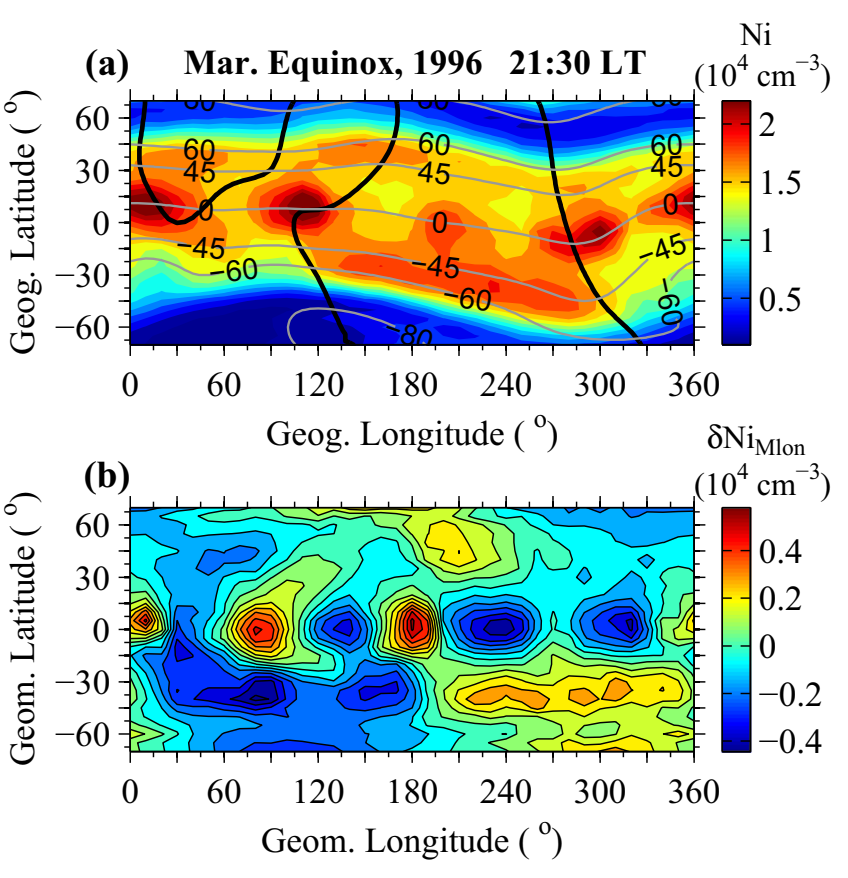

Fig. 3. (a) and (b) are same as Figures $1 \mathrm{a}$ and $1 \mathrm{c}$, respectively, but for DMSP F12 nightside measurements around the March Equinox of 1996. variation pattern is significantly different from that in the equatorial region; there is no conjugate effect between northern and southern mid-latitude longitude variations. $N_{i}$ longitude variations around the September Equinox are similar to those around the March Equinox; thus, we do not show them here. Figure 4 shows the average longitude and latitude variations of DMSP F12 $N_{i}$ at 21:30 LT around the December Solstice of 1996. Data of 57 days were used after removing the measurements under geomagnetic disturbance conditions. In general, there is also no prominent conjugate effect between the northern and southern longitude variations of mid-latitude $N_{i}$ around the December Solstice. Mid-latitude $N_{i}$ longitude variation is dominated by the one-peak structure in the Southern (summer) Hemisphere, with higher $N_{i}$ values around geomagnetic longitude $0^{\circ}$. Northern (winter) mid-latitude $N_{i}$ is correspondingly higher around geomagnetic longitude $0^{\circ}$; namely, northern and southern mid-latitude longitude variations are similar to some extent in this longitude sector. However, this similarity declines at other longitudes. In a word, the conjugate effect depends on seasons, evident conjugate effect was observed by the DMSP F12 satellite only in the June Solstice season of the solar minimum year 1996.

Solar activity dependence of the conjugate effect at the June Solstice was investigated using DMSP F12 measurements during solar cycle 23. Figure 5a shows the variation of the $F_{10.7}$ index (solar radio flux at the wavelength of $10.7 \mathrm{~cm}$ ) to 


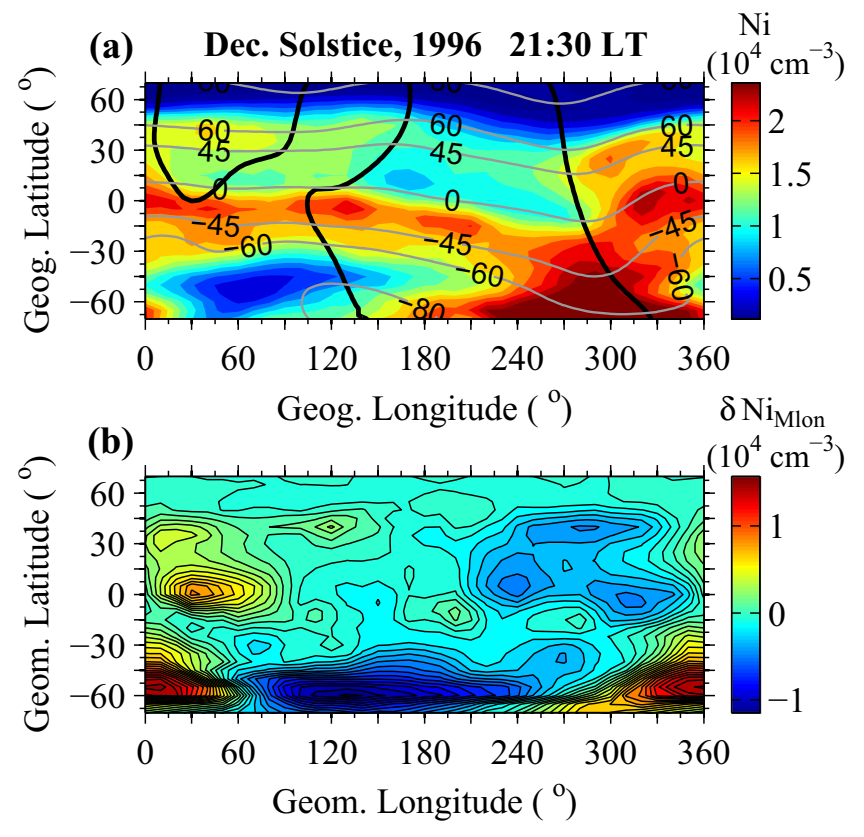

Fig. 4. (a) and (b) are same as Figures 1a and 1c, respectively, but for DMSP F12 nightside measurements around the December Solstice of 1996.

present solar activity condition. Solar activity reached low levels during 1995 to early 1997 and began to significantly increase since late 1997. Figures 5b-5h show the longitude fluctuations of $N_{i}$ averages measured by the DMSP F12 at nightside around the June Solstices of 1995-2001, respectively. Data of 46 (61, 57, 55, 55, 31, and 55) days in 1995 (1996, 1997, 1998, 1999,2000 , and 2001) were used after removing the measurements under geomagnetic disturbance conditions. The local time meridian which the DMSP F12 satellite was operated in shifted year by year, from 21:30 LT in 1996 to 19:50 LT in 2001. Conjugate longitude variations of mid-latitude $N_{i}$ took place more or less during the low solar activity period of 19951997, most prominent in 1996 when solar activity reached minimum. With increasing solar activity, the conjugate effect disappeared since 1998 and $N_{i}$ longitude variations in different years show similar patterns during 1999-2001, with one-peak structure at southern mid-latitudes and two-peak structure at northern mid-latitudes. This means that the conjugate effect after sunset only occurs at solar minimum.

\section{Discussion}

Although longitude variations of the mid-latitude ionosphere have been investigated in many previous papers (e.g., Burns et al., 2008; Horvath \& Lovell, 2009a; Jee et al., 2009; Lin et al., 2010; Zhang et al., 2012; Chen et al., 2016), the interhemispheric conjugacy of mid-latitude longitude variations has not been presented yet. Previous studies usually dealt with mid-latitude longitude variations in each hemisphere independently. In this study, we examined the similarities of the longitude variations at conjugate northern and southern latitudes. We found that longitude variations of topside $N_{i}$ at conjugate mid-latitudes are similar in solar minimum June Solstice season, exhibiting the interhemispheric conjugate effect.

This paper focuses on topside $N_{i}$ longitude variations. The topside ionosphere couples with the plasmasphere via the following charge-exchange reaction.

$$
\mathrm{O}^{+}+\mathrm{H} \rightleftharpoons \mathrm{O}+\mathrm{H}^{+}
$$

Ion compositions are significantly different between these two regions; the plasmasphere is dominated by protons while the ionospheric $\mathrm{F}_{2}$ region is dominated by ions $\mathrm{O}^{+}$. A diffusive barrier hinders free exchange of ions between the ionosphere and the plasmasphere (e.g., Park, 1970). Ionospheric $\mathrm{O}^{+}$must react with atoms $\mathrm{H}$ to produce protons and go through the diffusive barrier into the plasmasphere. The distribution of ion composition measured by the DMSP F12 satellite around the June Solstice of 1996, when the conjugate effect was observed, is presented in Figure 6. Light ions are dominant at southern low- to mid-latitudes until $\mathrm{O}^{+}$becomes dominant beyond $\sim 60^{\circ} \mathrm{S}$ (close to the plasmapause), indicating that $N_{i}$ measured by the DMSP F12 in fact corresponds to the density of the lower plasmasphere at southern mid-latitudes. In the Northern Hemisphere, however, the boundary $\left(\sim 45^{\circ} \mathrm{N}\right)$ separating light ions and $\mathrm{O}^{+}$is close to the solar terminator (see the dotted line in Fig. 6); $\mathrm{O}^{+}$is dominant beyond the solar terminator under the effect of the ionospheric $\mathrm{O}^{+}$upward diffusion caused by photoionization. That is to say, DMSP F12 $N_{i}$ corresponds to the plasmasphere at lower latitudes while to the ionosphere at higher latitudes in the Northern Hemisphere.

Dynamic mechanisms are usually used to explain ionospheric longitude variations. Neutral wind induced plasma transport and field-aligned diffusion are the primary dynamic processes in the mid-latitude ionosphere. Under the influence of the geomagnetic configuration, neutral wind induced transport causes longitude differences in the $\mathrm{F}_{2}$ layer height. This together with the contribution of photoionization are responsible for mid-latitude longitude variations, as described in previous studies (e.g., Horvath \& Lovell, 2009a; Jee et al., 2009; Zhang et al., 2012; Chen et al., 2016). These processes take place in the lower $\mathrm{F}_{2}$ region, where neutral winds can drive plasma fieldaligned movement via neutral-ion collisions. Neutral winds cannot directly drive plasma movement in the topside owing to the low neutral-ion collision rate; under the effect of sunlight, however, the topside plasma density can also be affected by the upward diffusion originating from the lower $F_{2}$ region. This may further affect the coupling between the topside ionosphere and the plasmasphere, since the charge-exchange reaction (Eq. 2) depends on the topside $\mathrm{O}^{+}$density. More ions can go through the diffusive barrier and couple into the plasmasphere when the ionospheric topside $\mathrm{O}^{+}$density is higher. The solar terminator at $300 \mathrm{~km}$ height is at geographic $29^{\circ} \mathrm{N}$ at $20: 30$ LT and at $40.5^{\circ} \mathrm{N}$ at 21:30 LT (this is also plotted in geomagnetic coordinates, see Fig. 1b). Thus, the northern mid-latitude $N_{i}$ distribution observed by the DMSP F12 at $840 \mathrm{~km}$ can be affected by the lower $\mathrm{F}_{2}$ region via upward diffusion and previous ionospheric coupling to the plasmasphere (at lower latitudes where light ions are dominant). In Figure 1a, northern midlatitude $N_{i}$ distribution shows a dependence on geomagnetic field configuration. In general, $N_{i}$ tends to be lower at the longitudes with larger inclinations, such as around $270^{\circ} \mathrm{E}$ where neutral wind induced transport is smaller since inclinations are 

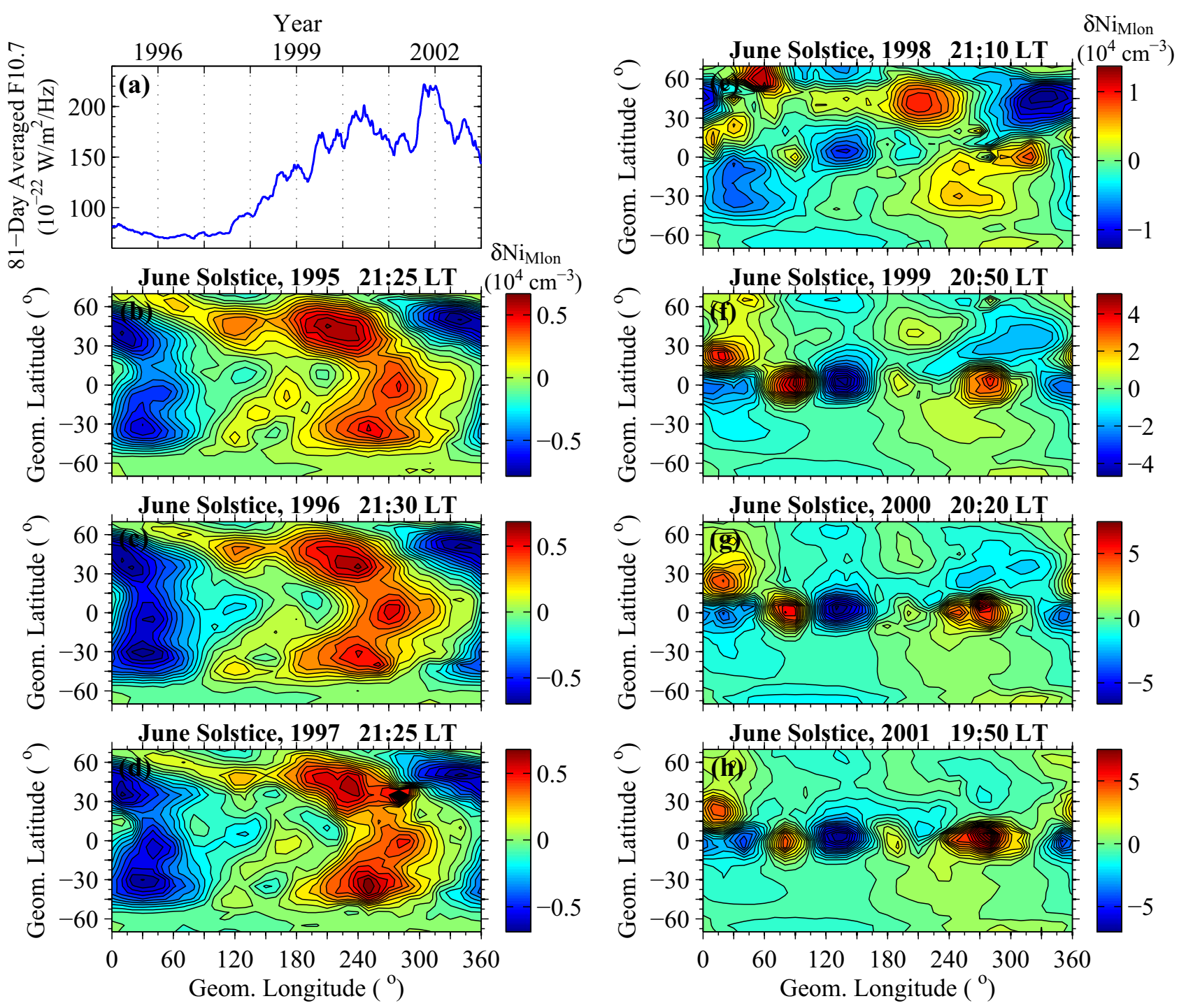

Fig. 5. (a) Variations of 81-day running averaged $F_{10.7}$ index from 1995 to 2002. (b-h) Same as Figure 1c but for DMSP F12 nightside measurements around the June Solstice of 1995-2001, respectively. The local time when the DMSP F12 satellite was over the equator is labeled at the top of each panel for reference; it shifted year by year.

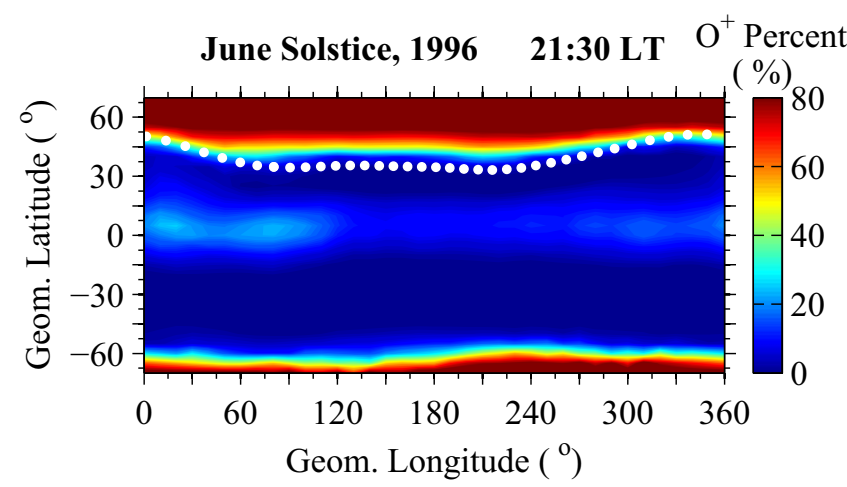

Fig. 6. Geomagnetic longitude and latitude variations of $\mathrm{O}^{+}$percent measured by the DMSP F12 at nightside 21:30 LT around the June Solstice of 1996. The white dotted line denotes the solar terminator at $300 \mathrm{~km}$ height at 21:30 LT. larger $\left(>45^{\circ}\right)$ and the vertical neutral wind is much smaller than the horizontal neutral winds under geomagnetic quiet condition (e.g., Fisher et al., 2015; Oyama et al., 2017), especially at higher latitudes (such as $45^{\circ}-60^{\circ} \mathrm{N}$ ) where the $\mathrm{F}_{2}$ peak region is still irradiated. Although geomagnetic declination is important for neutral wind induced vertical transport at mid-latitudes, inclination effects seem to be more important than declination effects in Figure 1a. For example, northern mid-latitude $N_{i}$ is lower around $300^{\circ} \mathrm{E}$ where declinations are negative and inclinations are larger, but these lower $N_{i}$ values extend westward to about $240^{\circ} \mathrm{E}$ where declinations are positive and inclinations are also larger. This indicates that geomagnetic inclinations are more important for the longitude variations of northern mid-latitude $N_{i}$ but does not mean declination effects are not important. In fact, the longitude variations of northern mid-latitude $N_{i}$ observed by the DMSP satellite are similar to previously observed dusk-to-nighttime electron density enhancements in the $F_{2}$ peak region (e.g., Chen et al., 2016) that 
were found to be closely related to neutral wind induced transport. These indicate that neutral wind induced transport plays an important role in the longitude variations of northern mid-latitude $N_{i}$.

It is nighttime in the Southern (winter) Hemisphere at 21:30 LT. The mid-latitude $\mathrm{F}_{2}$ layer begins to shrink after sunset in the winter, owing to plasma cooling contraction and quick plasma density decay at lower altitudes. This causes the topside plasma flux to become downward after sunset in solar minimum winter (Evans \& Holt, 1978), maintaining the mid-latitude nighttime $\mathrm{F}_{2}$ layer. Under this condition, the longitude variations of southern mid-latitude $N_{i}$ may be related to the downward flux from the upper plasmasphere. The plasmasphere couples with the ionosphere at both sides of the magnetic flux tubes (Kersley et al., 1978); it supplies the underlying ionosphere in the winter hemisphere and is replenished by the mid-latitude ionosphere in the summer hemisphere, where daytime lasts longer, at solstice night. It can be deduced that the summer mid-latitude ionosphere can affect winter midlatitude topside $N_{i}$ if there is an interhemispheric coupling inside the plasmasphere.

Low-latitude interhemispheric coupling is well-known and plays an important role in the electron density distribution. Horizontal neutral winds induce trans-equator plasma transport in the equatorial region where the apexes of geomagnetic field lines are lower, simplifying dynamic processes since the flux tubes inhabit only the $\mathrm{O}^{+}$dominated ionosphere. This can result in asymmetric electron density distributions with respect to the dip equator (e.g., Kil et al., 2006; Tulasi Ram et al., 2009; Chen et al., 2017). Low-latitude interhemispheric transport has been verified by low-Earth-orbit satellites based measurements (e.g., Burrell et al., 2013). For the mid-latitude ionosphere, however, the interhemispheric coupling is difficult to confirm directly from observations, since the apex heights of geomagnetic field lines are measured in units of Earth radii. Ionospheric plasma from one hemisphere must pass through the plasmasphere, where cold plasma transport is dominated by dipolar diffusion (e.g., Park, 1970), to arrive at the other hemisphere. The energies of charged particles are usually $\sim 1 \mathrm{eV}$ inside the plasmasphere (Chappell, 1972), corresponding to thermal velocities of $\sim 10 \mathrm{~km} / \mathrm{s}$ for protons. There are nearly no collisions between charged and neutral particles inside the plasmasphere. Thus, plasma diffusion is much faster inside the plasmasphere than in the ionosphere. This makes interhemispheric coupling through diffusion possible, with timescales on the order of hours. This interhemispheric coupling has been adopted in numerical calculations of two-way coupled ionosphere-plasmasphere systems (e.g., Bailey et al., 1978; Förster \& Jakowski, 1986, 1988; Jakowski \& Förster, 1995).

Mid-latitude interhemispheric coupling can well account for the conjugate longitude variations presented in Figure 1. On the one hand, neutral wind induced transport combined with the photoionization can cause longitude variations in the lower $\mathrm{F}_{2}$ region that subsequently affect the topside through upward diffusion at summer mid-latitudes; the topside ionosphere then affects the lower plasmasphere via the coupling through charge exchange. This can result in the longitude variations observed by the DMSP F12 satellite at northern (summer) mid-latitudes. On the other hand, the ion density of the plasmasphere declines at the southern (winter) side of magnetic flux tubes through downward diffusion into the ionosphere. The density difference between the northern and southern sides of flux tubes then results in a summer to winter interhemispheric coupling inside the plasmasphere. This can cause southern conjugate longitude variations if interhemispheric coupling plays a dominant role in $N_{i}$ longitude variations at $840 \mathrm{~km}$ at southern mid-latitudes. Certainly, the coupling course is not instantaneous; its rate depends on the dipolar diffusion inside the plasmasphere. A persuasive evidence for the interhemispheric coupling mechanism is presented in Figure 2. The conjugate effect occurs only inside the plasmapause at geomagnetic $\sim 60^{\circ}$ where $\mathrm{O}^{+}$percent sharply increases (Horvath \& Lovell, 2009b), as shown in Figure 6. Magnetic flux tubes are consistently closed inside the plasmapause, allowing sustained interhemispheric coupling to take place. Outside the plasmapause, although flux tubes are also closed till more than $70^{\circ}$ geomagnetic latitudes (latitude limit of closed flux tubes is highly dynamic since high-latitude flux tubes can undergo reconnection), magnetospheric convection does not allow the plasma within flux tubes to stably corotate with the Earth (Chappell, 1972 and references therein). As a result, the interhemispheric coupling cannot maintain. The conjugate longitude variations not only show the presence of interhemispheric coupling through the plasmasphere, but also imply that under the effect of geomagnetic configuration, neutral wind induced transport is important for ionospheric coupling to the plasmasphere at mid-latitudes.

DMSP F12 observations presented in Figure 5 indicate that conjugate longitude variations occurred at solar minimum years 1995-1997 and disappeared when solar activity significantly increased. We further confirmed conjugate longitude variations at solar minimum using DMSP F16 measurements during the deep solar minimum of 2007-2009, when solar activity was lower than during 1995-1997 (e.g., Chen et al., 2011; Solomon et al., 2011). The DMSP F16 satellite measured topside $N_{i}$ during that deep solar minimum at earlier local times than the DMSP F12 during 1995-1997. Figures 7a-7c show the longitude fluctuations of $N_{i}$ averages measured by the DMSP F16 around the June Solstices of 2007-2009, respectively. Data of 56 (61 and 60) days in 2007 (2008 and 2009) were used after removing the measurements under geomagnetic disturbance conditions. Conjugate mid-latitude longitude variations was also observed more or less by the DMSP F16 in 2007 and 2008, as presented in Figure 1, even though local times are earlier than DMSP F12 measurements. The conjugate secondary midlatitude $N_{i}$ peaks around $120^{\circ} \mathrm{E}$ became less evident in 2009 . This is possibly related to that the DMSP F16 shifted to earlier local times in 2009 so that the interhemispheric coupling did not fully form. Anyway, DMSP F16 measurements indicate again that the conjugate effect can occur at solar minimum.

Solar activity dependence of the conjugate effect is consistent with the interhemispheric coupling mechanism. Evans \& Holt (1978) presented that local time evolution of the ion flux between the ionosphere and the plasmasphere significantly depends on the solar activity levels according to the Millstone Hill incoherent scatter radar observations. The flux in winter becomes downward after sunset at solar minimum; however, it remains upward after sunset and becomes downward after midnight at solar maximum. This means there is no interhemispheric coupling at earlier nighttime hours at solar maximum so that the interhemispheric conjugate effect cannot be observed in 


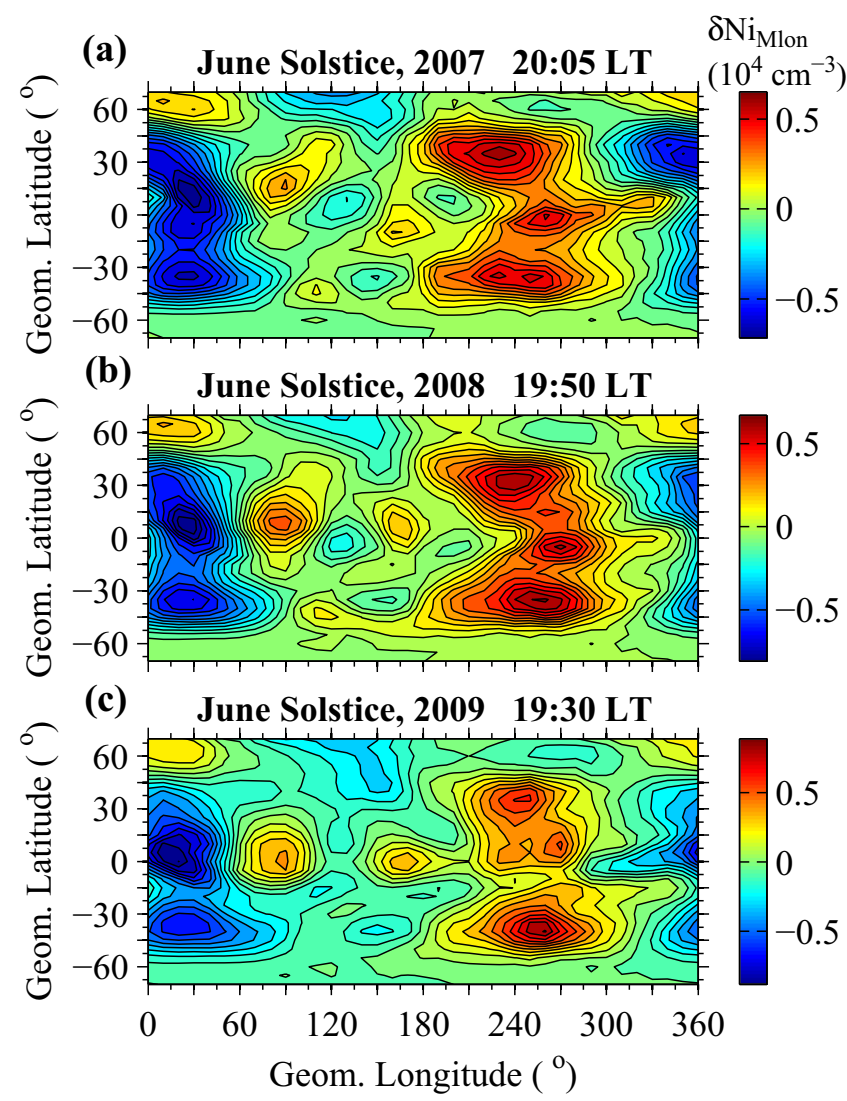

Fig. 7. Same as Figure 1c but for DMSP F16 nightside measurements around the June Solstice during the deep solar minimum of 2007-2009. The local time when the DMSP F16 satellite was over the equator is labeled at the top of each panel.

DMSP measurements. Therefore, solar activity dependence of the conjugate effect supports again the interhemispheric coupling mechanism.

Conjugate longitude variations do not occur at all longitudes around the December Solstice, except that the northern and southern main peaks of mid-latitude $N_{i}$ longitude variations show conjugacy around geomagnetic longitude $0^{\circ}$. One possible reason is the difference in DMSP orbit local time between the two hemispheres. Local time of DMSP F12 orbit is about $1 \mathrm{~h}$ earlier at northern (the winter hemisphere at the December Solstice) mid-latitudes than at southern mid-latitudes in nightside sector. As a result, Figure 4 possibly corresponds to the condition that the summer to winter interhemispheric coupling does not fully form to affect mid-latitude longitude variations in the winter hemisphere. Moreover, longitude variations of topside $N_{i}$ are also affected by local ionospheric transport processes in addition to the interhemispheric coupling. The longitude variations around the December Solstice need further investigations in future works.

\section{Summary}

Longitude variations of mid-latitude topside $N_{i}$ in both hemispheres were investigated using DMSP measurements.
Nightside $N_{i}$ measurements around the June Solstice were analyzed to investigate possible influences of the plasmasphere on the longitude variations of topside $N_{i}$, since the topside ion flux gradually becomes downward in the winter hemisphere after sunset at solar minimum. We presented, for the first time, the interhemispheric conjugate effect in mid-latitude longitude variations. $N_{i}$ longitude variation patterns are similar between equivalent northern and southern geomagnetic mid-latitudes around the June Solstice at solar minimum. The conjugate effect disappears once geomagnetic latitudes are beyond the footprint of the plasmapause. Conjugate longitude variations do not occur in other seasons and disappear when solar activity significantly increases.

Under the effect of geomagnetic field configuration, neutral wind induced ionospheric transport and upward diffusion caused by the photoionization in the lower $F_{2}$ region are responsible for the longitude variations of topside $N_{i}$ at summer mid-latitudes at solar minimum. The conjugate longitude variations at winter mid-latitudes can then be understood to form as a result of the summer to winter interhemispheric coupling through the plasmasphere. Consistent with the interhemispheric coupling mechanism, the conjugate effect exists only inside the plasmapause where magnetic flux tubes are closed and the plasma within these tubes can stably corotate with the Earth, so that the interhemispheric coupling can take place. The conjugate effect not only proves mid-latitude interhemispheric coupling through the plasmasphere, but also implies that neutral wind induced ionospheric transport can affect ionospheric coupling to the plasmasphere at mid-latitudes.

Acknowledgements. The authors thank the Center for Space Sciences at University of Texas at Dallas (http://cindispace. utdallas.edu/DMSP/) and the U.S. Air Force for DMSP/SSIES data service. This research was supported by National Natural Science Foundation of China (41621063 and 41674159) and Youth Innovation Promotion Association, CAS (grant No. 2016066). The editor thanks two anonymous referees for their assistance in evaluating this paper.

\section{References}

Bailey GJ, Moffett RJ, Murphy JA. 1978. Interhemispheric flow of thermal plasma in a closed magnetic flux tube at mid-latitudes under sunspot minimum conditions. Planet Space Sci 26(8): 753-765.

Burrell AG, Heelis RA, Stoneback RA. 2012. Equatorial longitude and local time variations of topside magnetic field-aligned ion drifts at solar minimum. J Geophys Res 117: A04304. DOI: 10.1029/2011JA017264.

Burrell AG, Heelis RA, Ridley A. 2013. Daytime altitude variations of the equatorial, topside magnetic field-aligned ion transport at solar minimum. J Geophys Res (Space Phys) 118: 3568-3575. DOI: 10.1002 /jgra.50284.

Burns AG, Zeng Z, Wang W, Lei J, Solomon SC, Richmond AD, Killeen TL, Kuo Y-H. 2008. Behavior of the F2 peak ionosphere over the South Pacific at dusk during quiet summer conditions from COSMIC data. J Geophys Res 113: A12305. DOI: 10.1029/ 2008JA013308.

Chappell CR. 1972. Recent satellite measurements of the morphology and dynamics of the plasmasphere. Rev Geophys 10: 951-979. 
Chen Y, Liu L, Wan W. 2011. Does the F10.7 index correctly describe solar EUV flux during the deep solar minimum of 2007-2009? J Geophys Res 116: A04304. DOI: 10.1029/2010JA016301.

Chen Y, Liu L, Le H, Wan W, Zhang H. 2015. NmF2 enhancement during ionospheric F2 region nighttime: A statistical analysis based on COSMIC observations during the 2007-2009 solar minimum. J Geophys Res (Space Phys) 120: 10083-10095. DOI: 10.1002/2015JA021652.

Chen Y, Liu L, Le H, Wan W, Zhang H. 2016. The global distribution of the dusk-to-nighttime enhancement of summer NmF2 at solar minimum. J Geophys Res (Space Phys) 121: 7914-7922. DOI: 10.1002/2016JA022670.

Chen Y, Liu L, Le H, Wan W, Zhang H. 2017. The effect of zonal wind reversal around sunset on ionospheric interhemispheric asymmetry at March equinox of a solar maximum year 2000. J Geophys Res (Space Phys) 122: 4726-4735. DOI: 10.1002/ 2017JA023874.

England SL, Immel TJ, Sagawa E, Henderson SB, Hagan ME, Mende SB, Frey HU, Swenson CM, Paxton LJ. 2006. Effect of atmospheric tides on the morphology of the quiet time, postsunset equatorial ionospheric anomaly. J Geophys Res 111: A10S19. DOI: $10.1029 / 2006 J A 011795$.

England SL, Immel TJ, Huba JD, Hagan ME, Maute A, DeMajistre R. 2010. Modeling of multiple effects of atmospheric tides on the ionosphere: An examination of possible coupling mechanisms responsible for the longitudinal structure of the equatorial ionosphere. J Geophys Res 115: A05308. DOI: 10.1029/2009JA014894.

Evans JV, Holt JM. 1978. Nighttime proton fluxes at Millstone Hill. Planet Space Sci 26: 727-744.

Finlay CC, Maus S, Beggan CD, Bondar TN, Chambodut A, Chernova TA, et al. 2010. International geomagnetic reference field: The eleventh generation. Geophys J Int 183: 1216-1230. DOI: 10.1111/j.1365-246X.2010.04804.x.

Fejer BG, Jensen JW, Su S-Y. 2008. Quiet time equatorial F region vertical plasma drift model derived from ROCSAT-1 observations. J Geophys Res 113: A05304. DOI: 10.1029/2007JA012801.

Fisher DJ, Makela JJ, Meriwether JW, Buriti RA, Benkhaldoun Z, Kaab M, Lagheryeb A. 2015. Climatologies of nighttime thermospheric winds and temperatures from Fabry-Perot interferometer measurements: From solar minimum to solar maximum. J Geophys Res (Space Phys) 120: 6679-6693. DOI: 10.1002/ 2015JA021170.

Förster M, Jakowski N. 1986. Interhemispheric ionospheric coupling at the American sector during low solar activity. II. Modelling. Gerlands Beitr Geophys 95: 301-314.

Förster M, Jakowski N. 1988. The nighttime winter anomaly (NWA) effect in the American sector as a consequence of interhemispheric ionospheric coupling. PAGEOPH 127: 447-471.

Greenspan ME, Burke WJ, Rich FJ, Hughes WJ, Heelis RA. 1994. DMSP F8 observations of the mid-latitude and low-latitude topside ionosphere near solar minimum. J Geophys Res 99: 3817-3826. DOI: 10.1029/93JA02287.

Hanson WB, Moffett RJ. 1966. Ionization transport effects in the equatorial F region. J Geophys Res 71: 5559-5572. DOI: 10.1029/ JZ071i023p05559.

Horvath I, Lovell BC. 2009a. An investigation of the northern hemisphere midlatitude nighttime plasma density enhancements and their relations to the midlatitude nighttime trough during summer. $J$ Geophys Res 114: A08308. DOI: 10.1029/ 2009JA014094.

Horvath I, Lovell BC. 2009b. Investigating the relationships among the South Atlantic Magnetic Anomaly, southern nighttime midlatitude trough, and nighttime Weddell Sea Anomaly during southern summer. J Geophys Res 114: A02306. DOI: 10.1029/ 2008JA013719.

Immel TJ, Sagawa E, England SL, Henderson SB, Hagan ME, Mende SB, Frey HU, Swenson CM, Paxton LJ. 2006. Control of equatorial ionospheric morphology by atmospheric tides. Geophys Res Lett 33: L15108. DOI: 10.1029/2006GL026161.

Jakowski N, Förster M. 1995. About the nature of the Night-time Winter Anomaly effect (NWA) in the F-region of the ionosphere. Planet Space Sci 43: 603-612.

Jakowski N, Hoque MM, Kriegel M, Patidar V. 2015. The persistence of the NWA effect during the low solar activity period 2007-2009. J Geophys Res (Space Phys) 120: 9148-9160. DOI: 10.1002/2015JA021600.

Jee G, Burns AG, Kim Y-H, Wang W. 2009. Seasonal and solar activity variations of the Weddell Sea Anomaly observed in the TOPEX total electron content measurements. J Geophys Res 114: A04307. DOI: 10.1029/2008JA013801.

Kersley L, Hajeb-Hosseinieh H, Edwards KJ. 1978. Plasma fluxes between ionosphere and protonosphere. Nature 271: 427-429.

Kil H, DeMajistre R, Paxton LJ, Zhang Y. 2006. Nighttime F-region morphology in the low and middle latitudes seen from DMSP F15 and TIMED/GUVI. J Atmos Solar-Terr Phys 68: 1672-1681.

Laundal KM, Richmond AD. 2017. Magnetic coordinate systems. Space Sci Rev 206: 27-59. DOI: 10.1007/s11214-016-0275-y.

Lin CH, Liu CH, Liu JY, Chen CH, Burns AG, Wang W. 2010. Midlatitude summer nighttime anomaly of the ionospheric electron density observed by FORMOSAT-3/COSMIC. J Geophys Res 115: A03308. DOI: $10.1029 / 2009 J A 014084$.

Liu H, Yamamoto M, Lühr H. 2009. Wave-4 pattern of the equatorial mass density anomaly: A thermospheric signature of tropical deep convection. Geophys Res Lett 36: L18104. DOI: 10.1029/ 2009GL039865.

Oyama S-i, Kubota K, Morinaga T, Tsuda TT, Kurihara J, Larsen MF, Yamamoto M, Cai L. 2017. Simultaneous FPI and TMA measurements of the lower thermospheric wind in the vicinity of the poleward expanding aurora after substorm onset. $J$ Geophys Res (Space Phys) 122: 10864-10875.

Park CG. 1970. Whistler observations of the interchange of ionization between the ionosphere and the protonosphere. J Geophys Res $\mathbf{7 5}$ : 4249-4260.

Ren Z, Wan W, Liu L, Xiong J. 2009. Intra-annual variation of wave number 4 structure of vertical $\mathrm{E} \times \mathrm{B}$ drifts in the equatorial ionosphere seen from ROCSAT-1. J Geophys Res 114: A05308. DOI: $10.1029 / 2009 J A 014060$.

Rich F. 1994. Technical description for the topside ionospheric plasma monitor (SSIES, SSIES-2 and SSIES-3) on spacecraft of the Defense Meteorological Satellite Program (DMSP), Technical Report PL-TR-94-2187. Air Force Phillips laboratory, Bedford, MA.

Solomon SC, Qian L, Didkovsky LV, Viereck RA, Woods TN. 2011. Causes of low thermospheric density during the 2007-2009 solar minimum. J Geophys Res 116: A00H07. DOI: 10.1029/ 2011JA016508.

Tulasi Ram S, Su S-Y, Liu C-H. 2009. FORMOSAT-3/COSMIC observations of seasonal and longitudinal variations of equatorial ionization anomaly and its interhemispheric asymmetry during the solar minimum period. J Geophys Res 114: A06311. DOI: 10.1029/2008JA013880.

VanZandt TE, Clark WL, Warnock JM. 1972. Magnetic apex coordinates: A magnetic coordinate system for the ionospheric F2 layer. J Geophys Res 77: 2406-2411. 
Wan W, Liu L, Pi X, Zhang M-L, Ning B, Xiong J, Ding F. 2008. Wavenumber- 4 patterns of the total electron content over the low latitude ionosphere. Geophys Res Lett 35: L12104. DOI: 10.1029/ 2008 GL033755.

Wan W, Ren Z, Ding F, Xiong J, Liu L, Ning B, Zhao B, Li G, Zhang M-L. 2012. A simulation study for the couplings between DE3 tide and longitudinal WN4 structure in the thermosphere and ionosphere. J Atmos Solar-Terr Phys 90: 52-60. DOI: 10.1016/ j.jastp.2012.04.011.

Zhang S-R, Foster JC, Holt JM, Erickson PJ, Coster AJ. 2012. Magnetic declination and zonal wind effects on longitudinal differences of ionospheric electron density at midlatitudes. J Geophys Res 117: A08329. DOI: 10.1029/2012JA017954.

Cite this article as: Chen Y, Liu L, Le H \& Zhang H 2019. Interhemispheric conjugate effect in longitude variations of mid-latitude ion density. J. Space Weather Space Clim. 9, A40. 